\title{
Orbital Vascular Malformation
}

"Athari A. Al-Obaidani, ${ }^{1}$ Sameer Raniga, ${ }^{2}$ Ayman Al Hadidi, ${ }^{3}$ Buthaina Sabt, ${ }^{4}$ Abdullah Al-Mujaini ${ }^{4,5}$

تشوه الأوعية الدموية الحجاجية

عذاري عبد الله العبيدانية، سمير رانيجا، أيمن الحديدي، بثينة سبت، عبد الله المجيني

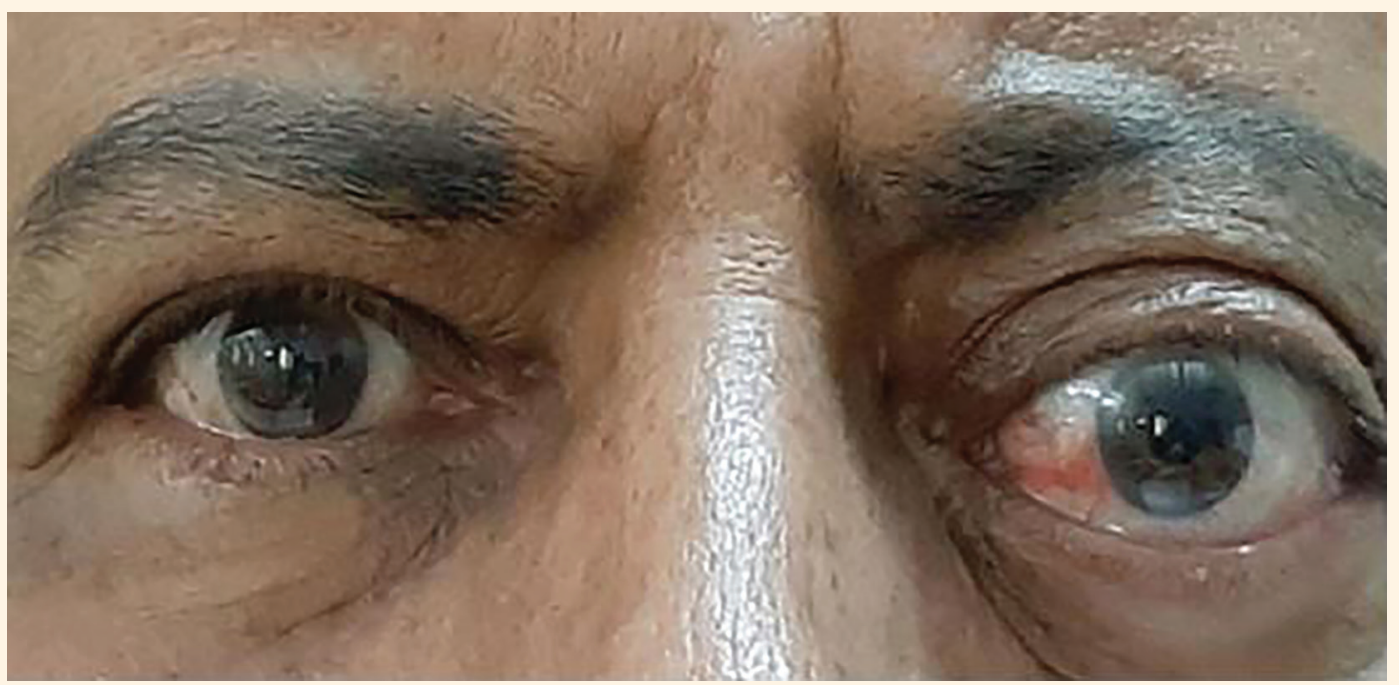

Figure 1: Photograph of the eyes of a 56 year-old male patient showing the left eye protruding outward (proptotic).

A

56-YEAR-OLD MALE PATIENT, KNOWN TO have hypertension, presented to the Sultan Qaboos University Hospital in 2019 with a six-year history of gradually increasing left eye protrusion associated with reduced vision in the left eye. Ophthalmic examination revealed a significant proptosis in the left eye with an inferior displacement of the globe [Figure 1]. The best-corrected visual acuity was $6 / 9$ and 6/24 in the right and left eye, respectively. Afferent pupillary defect was noted in the left eye, but slit-lamp biomicroscopy was unremarkable on both sides. Dilated fundus examination of the left eye showed an elevated optic disc with hazy borders. Left eye proptosis secondary to retrobulbar mass was the most likely aetiology and a magnetic resonance imaging (MRI) scan was performed.

The MRI scan showed an oval-shaped retrobulbar intraorbital lesion measuring $3.0 \times 2.7 \times 3.1$ $\mathrm{cm}$ (anteroposterior $\times$ craniocaudal $\times$ transverse) in size, displacing the orbit anteriorly, the optic nerve inferomedially and the superior and lateral rectus muscles peripherally [Figure 2]. The lesion showed high signal intensity in T2- and isointense signal in T1-weighted images with progressive enhancement starting as a patchy enhancement at the late arterial phase with a complete enhancement of the lesion in the delayed images [Figure 3]. Findings were consistent with orbital slow-flow vascular malformation which was likely a cavernous malformation.

Informed consent was obtained from the patient for the publication of these images.

\section{Comment}

Vascular lesions of the orbits are rare; the various types are charcterised by their growth, histopathology and flow. According to a system proposed by Mulliken and Glowacki, they are classified as capillary haemangiomas, venous vascular malformations, venous lymphatic malformations, arterial and arteriovenous lesions or neoplasms. ${ }^{1}$ 

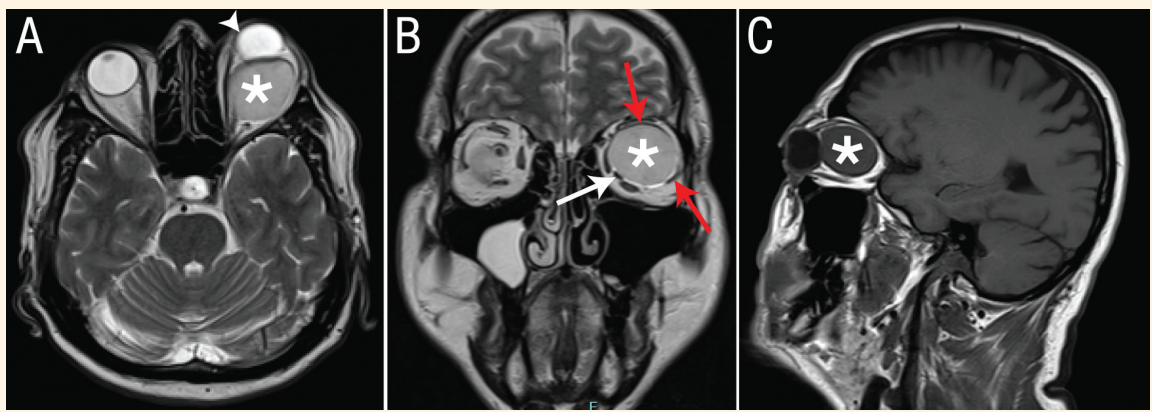

Figure 2: Multi-sequential multi-planar magnetic resonance images of the head (orbits with intravenous contrast) of a 56-year-old male patient. A \& B: Axial and coronal T2-weighted images showing an oval-shaped lesion (asterisk) in the retrobulbar intraconal space of the left orbit displacing the glob anteriorly (arrowhead), the optic nerve inferomedially (white arrow) and the superior and lateral rectus muscles (red arrows) peripherally. The lesion shows homogenous intermediate to high signal intensity in T2-weighted images. C: Sagittal precontrast T1-weighted image showing that the lesion is isointense to the cerebral cortex (asterisk).

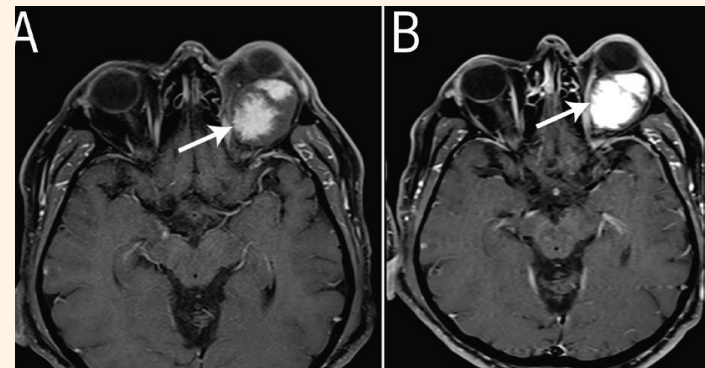

Figure 3: Axial T1-weighted post-intravenous Gadolinium-enhanced images in the (A) late arterial and (B) delayed phase showing progressive enhancement (solid white arrows). The lesion is almost completly enhanced on the delayed images.

Cavernous malformations are the most common orbital lesions in adults and account for $6 \%$ of all orbital masses. ${ }^{2}$ These lesions are slow-growing and often manifest with progressive, painless proptosis. They tend to be septate, well-circumscribed and do not involute. ${ }^{1}$ These lesions are usually located in the lateral aspect of intraconal retrobulbar space and are rarely found in the conal or extraconal spaces. ${ }^{3}$ Bone remodelling can be seen as well as calcifications. Associations with Maffucci syndrome and blue rubber bleb nevus syndrome have been reported. ${ }^{1}$

Cavernous malformations have a fibrous pseudocapsule and appear circumscribed on imaging. They usually appear hyperattenuated on computed tomography scan and occasionally contain phleboliths. In addition, they displace adjacent structures without invading them and may cause expansion of the orbital walls. On MRI, they appear isointense to the muscle in T1- and hyperintense to the muscle in T2-weighted images. In the early arterial phase, they show poor enhancement due to their slow flow nature with progressive accumulation of contrast material in the late phase dynamic and delayed images.

The management of these lesions should be individualised and determined by size, location and patient symptoms. Conservative management is advised if there are no or minimal symptoms. Sclerotherapy with ethanol injection is advised for an extensive facial with orbital/periorbital involvement. Other options include surgical excision for localised lesions or surgical resection for more extensive and deep lesions. ${ }^{4}$ All available measures and their risks and benefits should be discussed with the patient during peri-operative counselling.

\section{References}

1. Smoker WR, Gentry LR, Yee NK, Reede DL, Nerad JA. Vascular lesions of the orbit: More than meets the eye. Radiographics 2008; 28:185-204. https://doi.org/10.1148/rg.281075040.

2. Xian J, Zhang Z, Wang Z, Li J, Yang B, Chen Q, et al. Evaluation of $M R$ imaging findings differentiating cavernous haemangiomas from schwannomas in the orbit. Eur Radiol 2010; 20:2221-8. https://doi.org/10.1007/s00330-010-1774-y.

3. Anand R, Deria K, Sharma P, Narula M, Garg R. Extraconal cavernous hemangioma of orbit: A case report. Indian J Radiol Imaging 2008; 18:310-12. https://doi.org/10.4103/0971-3026.43849.

4. Benoiton LA, Chan K, Steiner F, FitzJohn T, Tan ST. Management of orbital and periorbital venous malformation. Front Surg 2017; 4:27. https://doi.org/10.3389/fsurg.2017.00027. 